\title{
The American Diabetes Association
}

\author{
BY JOHN A. REED, M.D.
}

$\mathrm{P}$ ROFESSIONAI, education, patient education, public education and case finding, and research are the four major interests of the American Diabetes İssociation, which was established and incorporated as a medical organization in 1940. The association is a nonprofit membership organization and the only national nongovernment or voluntary group in the field of diabetes in the United States.

During its early years, the American Diabetes Issociation was concerned largely with clinical investigation and basic research pertaining to the problems of diabetes mellitus. Recently, however, it has carried out many of the functions of a voluntary health agency, although it has maintained its identity in structure as a medical organization.

The broad objectives of the association, in the language of its constitution and bylaws, are "to further the general welfare through acquisition and dissemination of useful and accurate knowledge and information regarding diabetes mellitus and to undertake in the public interest such activities as will improve the physical welfare of persons having that disorder." To these ends, the association strives:

Dr. Reed, who served for 6 years as secretary of the American Diabetes Association, was elected second vice president of the association in June 1955. He is also an assistant clinical professor of medicine, George Washington University School of Medicine, and has served as a member of the National Advisory Arthritis and Metabolic Disease Council, National Institutes of Health, Public Health Service.
- To promote among physicians and others the free exchange of knowledge with respect to diabetes mellitus.

- To improve the standards of treatment.

- To promote medical research by individuals, hospitals, clinies, universities, and other institutions.

- To educate the public in the early recognition of the disease and in the importance of medical supervision of its treatment.

- To distribute accurate information to the general public by literature, meetings, and other appropriate means.

- To develop educational methods designed to give diabetic patients a better understanding of their disease.

- To encourage the formation of subsidiary groups which will cooperate actively with the association in its program.

The active membership of the association consists of about 2,000 physicians and persons in related scientific fields whose primary interest is in diabetes mellitus. In addition, there are associate, honorary, and corporate members, who assist in the organization's work but are not entitled to vote.

The affairs of the association are managed by a council, which is composed of 18 persons elected by and from the active membership, the 5 principal officers of the association, and the 3 most recent living past presidents.

Financial support for the organization comes from membership dues; self-supporting projects, such as a professional journal, a magazine for diabetic patients, and a series of postgraduate courses; voluntary contributions by individuals, primarily diabetic patients; and 
grants by corporations and foundations. 'The association does not engage in any general public fund-raising compaigns.

\section{Public Education and Case Finding}

Education of the public concerning the prevalence of diabetes mellitus and the necessity for early discovery of the disease is of major importance. The number of diabetic patients now under medical care has been estimated to be well over one million, and there is probably an almost equal number of persons who have the disease but are unaware of it. Diabetes stands eighth in the list of known causes of death.

I program of public education and case finding, known as the diabetes detection drive, was established about 7 years ago for the purpose of finding persons with undetected diabetes. The drive is directed through local affiliates of the American Diabetes Association and the committees on diabetes of county and State medical societies, with assistance from public health groups and various local organizations. Activities are conducted throughout the year, but the greatest effort is made in observance of Diabetes Week, which is the third week of November.

The American Diabetes Association uses all mass communications media to focus the attention of the public on the detection drive, while the local affiliates and the committees on diabetes of county and State medical societies obtain the support of newspapers and radio and television stations in their areas.

Any public or voluntary health group which desires to cooperate in the diabetes detection drive, and especially in Diabetes Week activities, may do so through a local affiliate of the II) A. In areas where there is no ADA affiliate, proposed plans may be channeled through the committee on diabetes of the county or State medical society, which, in the absence of an AI) affiliate, assumes full responsibility for the drive. Many health departments, of course, are also undertaking diabetes detection programs.

Other IIDA activities in public education inclucle the showing of an exhibit entitled,
"What is IDiabetes?" 'This exhibit, which was prepared by the association in 1954, has already been shown at county fairs and medical centers in 17 cities. Ten sets of the exhibit are now in circulation.

\section{Professional Education}

Mlthough the American Diabetes Issociation is one of the younger medical groups, it already has developed a broad program of professional education for its members. This program includes annual scientific meetings; an annual postgraduate course in diabetes and basic metabolic problems; publication of the monthly professional journal Diabetes: publication of the Diabetes Guide Book for the Physician, of which more than 150,000 copies have been distributed; preparation and showing of exhibits ; and community meetings of the physician membership of the local affiliates.

The postgraduate course, which has been offered yearly since 1953 , provides refresher and review training for persons engaged in the clinical practice of diabetes mellitus and for those preparing for American Board of Internal Medicine examinations. The American Academy of General Practice allows 20 hours of postgraduate credit to persons who attend the course. The course is under the direction of the association, and the faculty consists of outstanding men in the fields of clinical metabolism and experimental metabolism. The third in the series was presented January 19 through 21, 195.5, at the Lankenau Hospital, Philadelphia.

To date, the association has prepared three exhibits for use in professional education: "IDiabetes Detection by the Physician," "Vascular Complications of Diabetes," and "Management of Diabetes Mellitus." These are shown regularly at the annual meetings of the American Medical Association and the American Academy of General Practice, and at State and regional medical meetings throughout the Enited States.

\section{Patient Education}

Patient education is a phase of the association's program which is almost limitless in its 
scope. One of its most far-reaching activities is the publication of a bimonthly magazine for diabetic patients, the ADA Forecast, which is now 8 years old. Written and edited for diabetic patients, it contains contributions by medical authorities and many articles by patients themselves. In response to requests from patients and their families, reprints have been made available of a large number of informative articles selected from back issues of the publication.

Answering inquiries from diabetic patients and their families is another activity of importance. Each year, the association receives several thousand letters asking questions about diabetes mellitus. Some can be answered with printed materials, but those asking specific questions receive the careful attention of competent medical men.

For use in teaching diabetic patients about their ailment and its control, the association has cooperated with the Public Health Service in producing an audiovisual kit. Also, it has cooperated with the Public Health Service and the American Dietetic Association in the publication of food exchange pamphlets and food lists for use by patients.

The ADA Committee on Employment has set up standards of employment for persons with diabetes. These standards have been of considerable value to employers and patients alike.

In addition to these activities, many of the local affiliates have formed societies of laymen for the purpose of providing mass instruction and general discussion on diabetes for patients and other interested persons.

\section{Research}

Through special gifts and grants, research funds have been established for the purpose of widening the knowledge of diabetes mellitus and its control. At the present time, the research program is limited to the granting of fellowships. Dr. Charles H. Best, co-discoverer of insulin, is chairman of the association's Committee on Research and Fellowships, which includes eight eminent investigators and clinicians.

\section{Affiliate Diabetes Associations}

To assist the American I Diabetes Isiociation in fulfilling its objectives, local affiliate units have been established throughout the Inited States. Is of .June 5. 1955, there were 39 such affiliates. Each of these has a clinical society. and many of them also have lay societies composed of diabetic patients, their relatives, and their friends.

The members of the committee on rliabetes of the county or State medical society are usually members, and sometimes officers, of the local affiliate. In fact, before an affiliate of the American Diabetes Association is formed, prior official endorsement must be obtained from the appropriate medical society through its committee on diabetes. This close cooperative effort provides a firm foundation on which to build an affiliate.

The affiliate serves the community by bringing together the physicians who are primarily interested in the disorder and the diabetic patients, their families, and their friends.

In order to strengthen the ties between the national organization and the affiliate, the comcil of the IDA has set up a Board of Governors. composed of a representative from almost each State and two from some of the larger ones. The governor functions as a liaison between the national organization and the local groups. He will participate in the development of all phases of the $\triangle D \Lambda$ program, particularly the strengthening of existing affiliates and the formation of new ones. Because of his awareness of the local situations, the governor is in an excellent position to serve in the capacity of adviser.

The governor also serves as senior delegate from his respective State to the ADA Assembly of Delegates, which is an advisory body to the ADA Council. Each affiliate also elects one physician and one layman, if there is a lay society, to the Assembly of Delegates.

One of the projects of great interest in the affiliates is the support of camps for diabetic children. It the present time, there are $2 t$ such camps, most of which are owned or sponsored by affiliates. These camps afford opportunities to educate the children in the maintenance of proper control of their condition. as 
well as to provide for them ordinary camping experiences. The affiliates also promote professional and nonprofessional education in diabetes in their own communities through lectures and public forums, and they are a major force in the conduct of the ammual diabetes detection drive.

\section{Toward Early Control}

Because of the degenerative complications which develop in a high percentage of diabetic patients, it is of utmost importance that control of the disease be established early and maintained. It is generally accepted that good chemical control of the disease prevents the disabling complications to a great extent. With proper treatment, a person with diabetes can work efficiently and with no more loss of time from the job than a person who does not have this ailment. It has been estimated that there are now nearly 200,000 diabetic patients in the labor force.

Diet is the essential part of control, but insulin in addition to diet is necessary in about 50 to 75 percent of the cases. Through close cooperation between the patient and the physician, good diabetic care can be achieved. The life span of the diabetic patient today can be practically normal.

Over and above the current program, a great deal must be done to accomplish the American Diabetes Association's four major objectives. For the immediate future, the association will seek an increase in the number of affiliate associations; an extension of the postgraduate course series, especially to regional and State levels; expansion of the diabetes detection drive; and an increase in the number of fellowships for research work.

\section{National Sanitary Engineers' Register}

At the request of the Office of Defense Mobilization, the Public Health Service is developing a National Register of Sanitary Engineers, as a phase of the program of the National Science Foundation.

In 1949, the American Public Health Association prepared a National Roster of Sanitary Engineers for the National Security Resources Board. Maintenance of that roster was discontinued a few years ago. The Public Health Service used that list and drew on the association's experience.

The American Public Health Association, the American Society of Civil Engineers, the American Water Works Association, the Federation of Sewage and Industrial Wastes Association, the Conference of Public Health Engineers, the Conference of State Sanitary Engineers, and the registration boards in each State have supplied their membership lists. A master mailing list of over 10,000 names of sanitary engineers has been developed from these and other sources.

A 1-page information sheet, prepared in cooperation with the Engineers' .Joint Council and the National Science Foundation, will be sent to each engineer whose name is on this list. A letter from Assistant Surgeon (General Mark I). Hollis, chief engineer of the Public Health Service, to accompany the information sheet, will ask each recipient to read the National Research Council's definition of a smitary engineer before transmitting his reply. By this means, details on the engineer's education, his professional experience, and his sanitary engineering specialty will be recorded on the register. 